\title{
METODE ALGORITMA DECISION TREE C4.5 UNTUK ANALISIS KELAYAKAN KREDIT NASABAH PADA BSM KCP KEMANG PRATAMA
}

\author{
Dyah Wulandari ${ }^{1}$, Nur Lutfiyana ${ }^{2,}$ Heny Sumarno ${ }^{3}$ \\ ${ }^{2}$ Jurusan Sistem Informasi, STMIK Mercusuar \\ Jurusan Sistem Informasi, STMIK Nusa Mandiri \\ e-mail: ${ }^{1}$ diyah.wndari87@gmail.com, ${ }^{2}$ nur.lutfiyana@yahoo.com, ${ }^{3}$ heny_nyno@yahoo.com
}

\begin{abstract}
Credit is the provision of money or equivalent claims, based on agreements or agreements on loans between banks and other parties which require the borrowing party to repay the debt after a certain period of time with the amount of interest, compensation or profit sharing. From the credit customer data available at BSM KCP Kemang Pratama still has Non Performing Financing (NPF) or Bad Credit.In analyzing a credit sometimes an analyst does an inaccurate analysis, so there are some customers who are less able to make credit payments, resulting in bad credit. So the researchers conducted an analysis using the C4.5 decision tree algorithm and Rapid Miner application for determining credit worthiness. From the analysis of credit customer data using the C4.5 decision tree algorithm method, the feasibility of credit recipient customers is very effective and produces a value of accuracy on Rapid Miner 5.3 of $80 \%$, Precision of $100 \%$ and Recall of $0 \%$ so as to minimize the risk.
\end{abstract}

Keywords-Credit, C4.5 Algorithm, Rapid Miner, Value Accuracy

\begin{abstract}
Abstrak - Kredit merupakan penyediaan uang atau tagihan yang dapat disamakan dengan hal itu, berdasarkan persetujuan atau kesepakatan pinjaman-pinjaman antara bank dengan pihak lain yang mewajibkan pihak peminjam untuk melunasi utangnya setelah jangka waktu tertentu dengan jumlah bunga, imbalan atau pembagian hasil keuntungan. Dari data nasabah kredit yang ada pada BSM KCP Kemang Pratama masih memiliki Non Performing Financing (NPF) atau Kredit Macet. Dalam menganalisa sebuah kredit terkadang seorang analis melakukan analisa tidak akurat, sehingga ada beberapa nasabah yang kurang mampu dalam melakukan pembayaran kredit, dan pada akhirnya mengakibatkan kredit macet. Peneliti melakukan analisis menggunakan algoritma decision tree C4.5 dan aplikasi Rapid Miner untuk penentuan kelayakan pemberian kredit. Dari analisis data nasabah kredit menggunakan metode Algoritma decision tree C4.5 menghasilkan kelayakan nasabah penerima kredit sangat efektif dan menghasilkan nilai akurasi pada Rapid Miner 5.3 sebesar $80 \%$, Precision sebesar $100 \%$ dan Recall sebesar $0 \%$ sehingga dapat meminimalisir resiko yang terjadi.
\end{abstract}

\section{Kata kunci-Kredit, Algoritma C4.5, Rapid Miner, Nilai Akurasi}

\section{A. PENDAHULUAN}

Diantara berbagai kebijaksanaan ekonomi yang dilaksanakan pemerintah, bidang perbankan merupakan salah satu bidang yang mendapat perhatian pemerintah karena bank merupakan salah satu sumber permodalan yang sangat dibutuhkan oleh masyarakat. Bank merupakan salah satu rekan pemerintah yang dituntut peran sertanya untuk mensukseskan pembangunan, melalui jasa kredit yang sangat dibutuhkan masyarakat dalam menjalankan kegiatan usaha.

Pada lembaga keuangan perbankan di Indonesia berlaku dual banking system, artinya terdapat dua sistem bank yang berlaku yaitu Bank Konvensional dan Bank Syariah salah satunya menggunakan system bagi hasil (profit dan sharing).

Dari keadaan ini, Bank Konvensional dan Bank Syariah bersaing secara terbuka dalam menarik nasabah. Kedua Bank tersebut berusaha menawarkan berbagai produk bank yang variatif dan berusaha meningkatkan pelayanan yang terbaik bagi nasabahnya.

Pada Bank Konvensional yang menggunakan instrument bunga pada operasinya, bunga tersebut menjadi sumber pendapatan bank dan nasabah. Sedangkan pada Bank Syariah lebih variatif dalam menawarkan produknya. Tetapi yang paling prinsipil, produk Bank Syariah sangat menghindari instrument bunga.

Sistem bagi hasil (profit sharing) yang merupakan karakter dasar dari Bank Syariah adalah sebuah bentuk kesepakatan yang 
dibuat oleh pihak bank dengan pihak nasabah mengenai bagi hasil.

Bank Syariah Mandiri merupakan Bank Umum Syariah ke-2 di Indonesia setelah berdirinya Bank Muamalat Indonesia, sekitar tahun 1992. Sejarah berdirinya Bank Syariah Mandiri dipengaruhi adanya tuntutan dari sebagian masyarakat muslim Indnesia yang menganggap bahwa bunga bank adalah haram.

Dalam kegiatan bank syariah dikenal dengan nama pembiayaan atau yang biasa kita kenal dengan nama kredit. Pembiayaan atau kredit merupakan salah satu tugas pokok bank. Kegiatan pembiayaan secara umum pada bank syariah antara lain pembiayaan berdasarkan prinsip bagi hasil (mudharabah), penyertaan modal (musyarakah), prinsip jual beli barang dengan memperoleh keuntungan (murabahah), atau pembiayaan barang modal berdasarkan prinsip sewa murni tanpa pilihan (ijarah) atau dengan adanya pilihan pemindahan kepemilikan atas barang yang disewa dari pihak bank oleh pihak lain (ijarah waiqtina).

Melalui data nasabah yang ada pada Bank Syariah Mandiri KCP Kemang Pratama, diharapkan dapat diterapkan suatu potensi untuk menentukan kriteria-kriteria apa saja yang dibutuhkan dalam seleksi calon nasabah kredit yang lebih berkualitas. Dari data nasabah kredit yang ada terlihat bahwa Bank Syariah Mandiri KCP Kemang Pratama masih memiliki Non Performing Financing (NPF) atau Kredit macet.

Kredit macet merupakan salah satu resiko kredit yang dihadapi oleh industry keuangan. Kredit macet terjadi apabila dalam jangka panjang, lembaga keuangan tidak dapat menarik pinjaman kredit dalam waktu yang ditentukan. Penilaian kredit dapat digunakan untuk membantu analisa kredit dalam menentukan kelayakan pemohon. Dengan model penilaian kredit yang tepat, bank dapat mengevaluasi apakah pemohon layak untuk mendapatkan kredit atau tidak.(Khasanah: 2017).

Algoritma Decision Tree C4.5 merupakan salah satu metode yang dapat menganalisis data dalam jumlah yang banyak atau biasa disebut DataMining. Pada penelitian ini dibuat suatu analisa pohon keputusan dengan algoritma C4.5, data yang digunakan dalam penelitian ini adalah data nasabah kredit.

Diperlukan penganalisaan yang tepat, khususnya dalam pemberian kredit untuk menghasilkan suatu keputusan kelayakan penerimaan kredit bagi nasabah sehingga meminimalisasikan terhadap resik. Oleh sebab itu dapat mencoba mengambil judul penelitian "Analisis Kelayakan Kredit Nasabah Pada Bank Syariah Mandiri KCP Kemang Pratama Dengan Menggunakan Metode Algoritma Decision Tree C4.5".

\section{B. TINJAUAN PUSTAKA}

Analisis dalam pengertian umum adalah suatu kegiatan untuk menyelidiki, menguraikan dan menelusuri akar persoalan suatu masalah. Kegiatan analisis merupakan langkah awal untuk mencari dan menemukan solusi terbaik mengatasi masalah yang dihadapi. Tanpa analisis yang "benar", "tepat", dan "spesifik". Maka sangat tidak mungkin seorang peneliti mampu menemukan jalan keluar terbaik mengatasi masalah yang dihadapi. Apalagi masalah yang dihadapi dalam kasus ini adalah dunia kredit macet atau yang sering dikenal dengan sebutan NPF atau Non Performing Financing. Berbeda dengan halnya mencari atau menemukan kerusakan suatu mesin dalam suatu sistem. (Jopie, 2010).

Kelayakan kredit adalah penilaian terhadap kemampuan dan kesediaan peminjam untuk melunasi kewajiban utangnya. Kelayakan kredit ditentukan oleh analis.Kombinasi faktor kuantitatif dan kualitatif termasuk ketersediaan agunan, leverage ratio, interest converage, dan keragaman dan stabilitas aliran pendapatan. (Fahmi, 2014).

Non Performing Financing adalah kredit bermasalah yang terdiri dari kredit yang mengklasifikasi kurang lancer, diragukan dan macet. Rasio yang digunakan untuk mengukur resiko terhadap kredit yang disalurkan dengan membandingkan kredit macet dengan jumlah kredit yang disalurkan. (Ihsan, 2013)

Rasio ini dirumuskan sebagai berikut:

NPF $=$ kredit bermasalah $\times 100 \%$ Total kredit yang diberikan

Data mining merupakan teknologi baru yang sangat berguna untuk membantu perusahaan-perusahaan menemukan informasi yang sangat penting dari data mereka. Data mining meramalkan tren dan sifat-sifat perilaku bisnis yang sangat berguna untuk mendukung pengambilan keputusan penting. Analisis yang diotomatisasi yang dilakukan oleh data mining melebihi yang dilakukan oleh system pendukung keputusan tradisional yang sudah banyak digunakan. Data mining dapat menjawab pertanyaan- 
pertanyaan bisnis yang dengan cara tradisional memerlukan banyak waktu untuk menjawabnya. (Nugroho \& Sulistyo, 2011).

Algoritma C4.5 mengkonstruksi pohon keputusan dari data pelatihan, yang berupa kasus-kasus atau record (tupel) dalam basis data. Setiap kasus berisikan nilai dari atributatribut untuk sebuah kelas. Setiap atribut dapat berisi data diskret atau kontinyu (numerik). C4.5 juga menangani kasus yang tidak memiliki nilai untuk sebuah atau lebih atribut. Akan tetapi, atribut kelas hanya bertipe diskret dan tidak boleh kosong. (Kamagi \& Hansun, 2014).

Algoritma C4.5 adalah algoritma klasifikasi pohon keputusan (decision tree). Pohon keputusan algoritma C4.5 dibangun dengan tiga tahap yaitu pemilihan atribut sebagai akar, membuat cabang untuk tiap-tiap nilai dan membagi kasus dalam cabang. Tahap-tahap ini akan diulangi untuk setiap cabang sampai semua kasus pada cabang memiliki kelas yang sama. Dari penyelesaian pohon keputusan maka akan di hasilkan beberapa rule atau pengetahuan dari suatu kasus. (Lusinia, 2014).

\section{METODE PENELITIAN}

Metode analisis data yang digunakan adalah Metode algoritma klasifikasi C4.5. Metode ini merupakan salah satu metode yang ada pada teknik klasifikasi dalam data mining. Metode pohon keputusan mengubah fakta yang sangat besar menjadi pohon keputusan yang merepresentasikan aturan. Pohon keputusan juga berguna untuk mengekplorasi data, menemukan hubungan tersembunyi antara sejumlah calon variabel input dengan sebuah variabel target. Data dalam pohon keputusan biasanya dinyatakan dalam bentuk table dengan atribut dan record. Atribut menyatakan suatu parameter yang

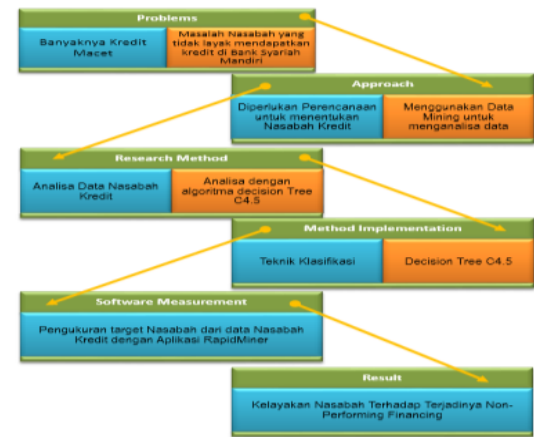

disebut sebagai kriteria dalam pembentukan pohon keputusan.

Sumber : Hasil Penelitian (2019)

Gambar.1 Kerangka Pemikiran

\section{HASIL DAN PEMBAHASAN}

Data mining merupakan proses mencari pola atau informasi menarik dalam data yang terpilih dengan menggunakan teknik atau metode tertentu. Pada penelitian ini penerapan data mining menggunakan teknik Classification dan algoritma decision tree C4.5 untuk mengetahui variabel penentu hasil Lancar atau tidaknya nasabah. Tahap data mining merupakan inti dari tahapan KDD yang dilakukan untuk menganalisis data yang sudah bersih.

Data yang digunakan dalam analisa ini adalah data sekunder yang diperoleh langsung dari laporan histories yang telah tersusun dalam arsip yang tidak dipublikasikan. Dan perangkat lunak yang digunakan dalam penelitian ini yaitu aplikasi RapidMiner 5.3 dengan menggunakan datawarehouse yang telah dihasilkan melalui tahapan awal dalam data mining maka langkah berikutnya adalah melakukan proses analisis data mining dengan teknik classification dan Algoritma decision tree C4.5.

\section{Analisis Node 1}

Dari 600 data nasabah tersebut dapat dilakukan perhitungan manual dengan cara menghitung entropy dan gainnya, maka didapatlah hasil perhitungan sebagai berikut:

$\left(\operatorname{Entropy}(S)=\sum_{1=1}^{n}-\mathrm{p} i \cdot \log 2 \mathrm{p} i\right)$

Entropy (Total)

$=(-\underline{480} * \log 2(\underline{480}))+(-\underline{120} * \log 2(\underline{120}))=0.2173220$

$\begin{array}{crrr}600 & 600 & 600 & 600\end{array}$

$=(-\underline{180} * \log 2(\underline{180}))+\left(-\underline{30}{ }^{*} \log 2(\underline{30})\right)=0.1781111$ $210 \quad 210-210-210$

Entropy (Angsuran 2)

$=\left(-\frac{60}{60}{ }^{*} \log 2(\underline{60})\right)+\left(-\underline{0}{ }_{60}{ }^{*} \log 2(\underline{0})\right)=0$

Gain (S, A) = Entropy (S) - $\sum_{i=0}^{n} \frac{\left|S_{1}\right|}{|S|}$ * Entropy $\left(S_{i}\right)$

Agar mudah dibacanya maka hasil perhitungan manual dapat ditabelkan seperti berikut: 
Tabel 1. Perhitungan Node 1

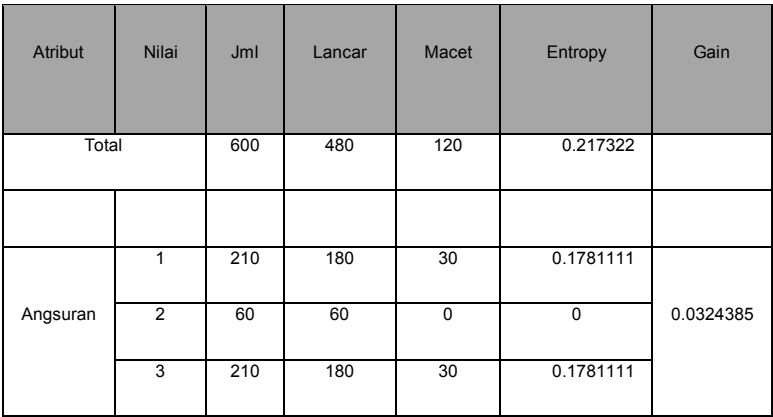

Sumber : Hasil Data Penelitian (2019)

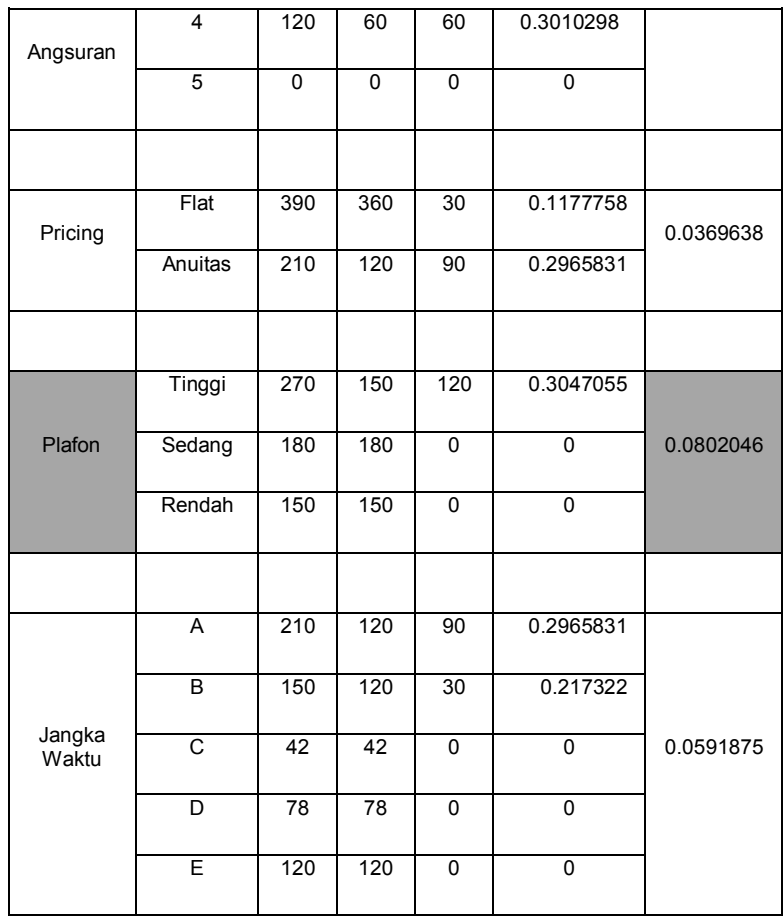

Maka didapatkanlah nilai gain tertinggi yaitu Plafon.Dihasilkan klasifikasi data yang diproses dengan konsep algoritma C4.5 dan di aplikasi RapidMiner menggunakan Modelling Decision Tree. Hasil klasifikasi data perhitungan manual dan yang menggunakan aplikasi RapidMiner ialah sebagai berikut:

\section{Hasil Dengan Mengunakan Manual Algoritma C4.5}

Hasil perhitungan manual terhadap 600 data nasabah kredit dengan menentukan beberapa node dan ini adalah tabel hasil perhitungan node
Tabel 2. Hasil Perhitungan Manual Algoritma C4.5 Node 1

Sumber : Hasil Data Penelitian (2019)

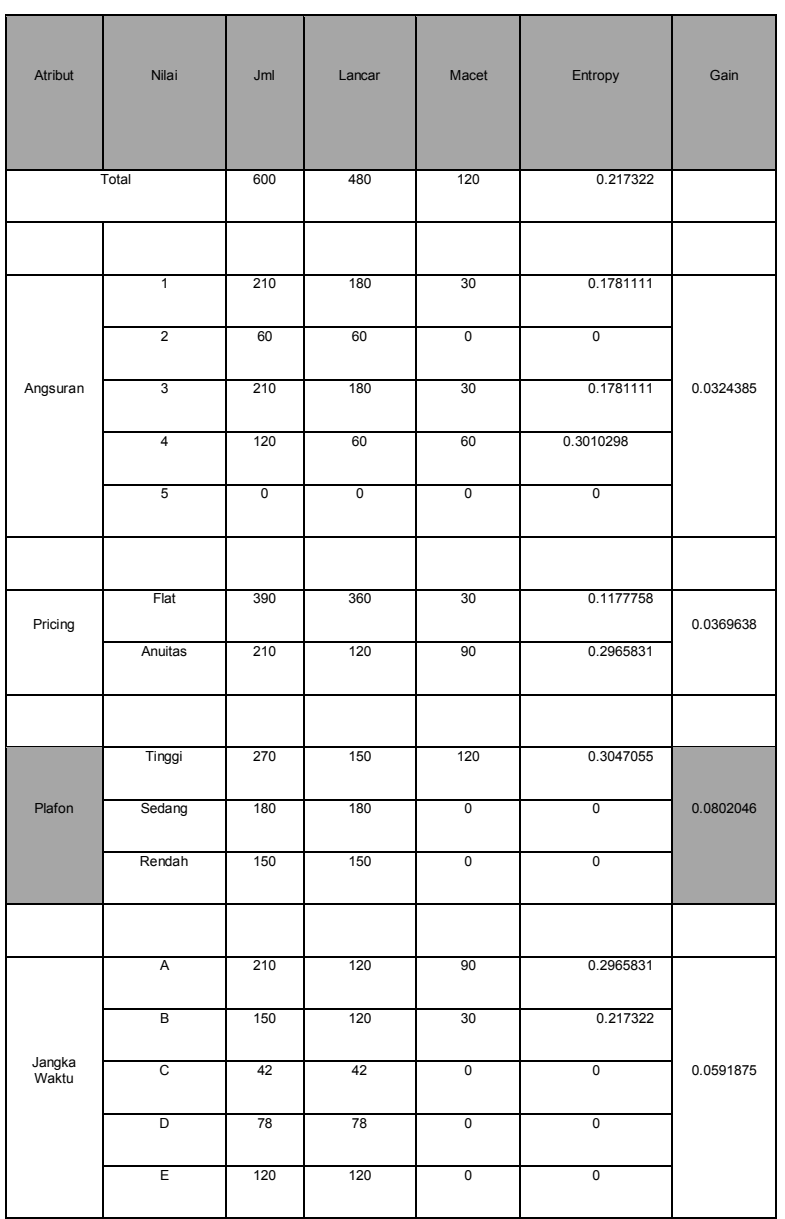

Dari tabel perhitungan node 3 tersebut dapat ditemukan gain tertinggi yaitu Angsuran dengan pembentukan pohon keputusan node 3 ini dinamakan pohon keputusan akhir, karena melihat hasil dari tabel diatas bahwa untuk leaf nilai penghasilan 1, 2, 3 dan 4 memiliki hasil sama dengan jumlah kasusnya masing-masing. Sedangkan Angsuran 5 tidak memiliki nilai maka perhitungan berhenti. 


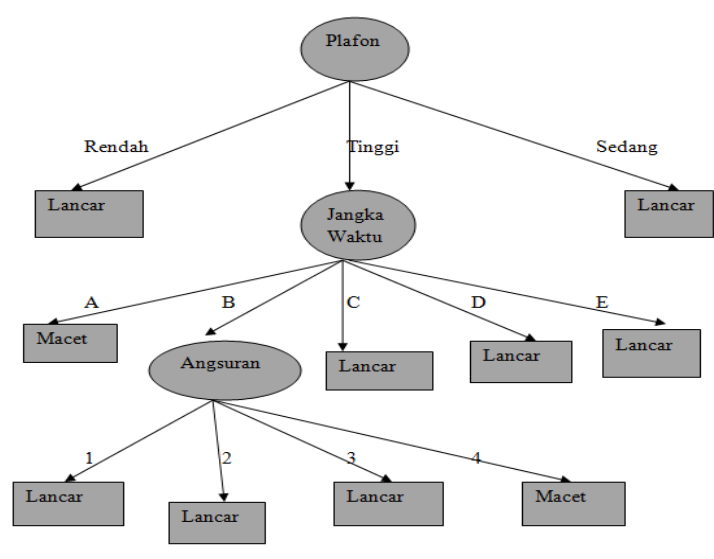

Sumber : Hasil Data Penelitian (2019)

Gambar 2. Hasil Pohon Keputusan Akhir

Perhitungan Manual

Hasil Dengan Perhitungan Aplikasi RapidMiner 5.3. Ada beberapa hasil yang didapat dari perhitungan menggunakan aplikasi rapidminer yaitu:

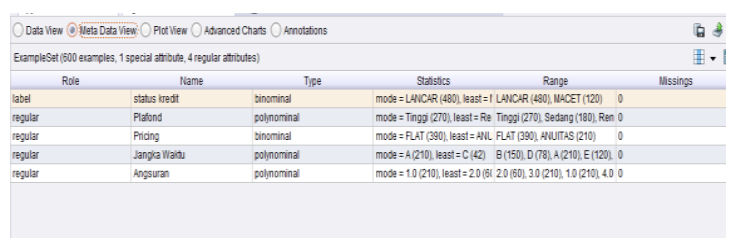

Sumber : Hasil Data Penelitian (2019)

\section{Gambar 3.. Meta Data View Aplikasi RapidMiner 5.3}

Pada saat menggunakan data nasabah kredit dengan menggunakan RapidMiner dalam mengklasifikasikan di aplikasi RapidMiner dari Meta Data View dapat dilinat ada 600 record data diklasifikasikan sebagai class "Lancar", 480 record data yang diklasifikasikan sebagai class "Macet" 120 record.

Diketahui bahwa nilai atribut Plafon memiliki nilai gain tertinggi, sehingga atribut ini menjadi atribut akar pada decision tree, kemudian dilanjutkan dengan atribut Jangka waktu dan dilanjutkan dengan atribut Jangka Waktu diakhiri oleh label kategori "Lancar" dan "Macet" yang berfungsi sebagai leaf. Maka dapat dikatakan bahwa parameter penentuanNasabah Kredit Lancar atau Macet baru dapat dilihat dari Plafon.

Sedangkan atribut pada Pricing gain yang diperoleh kecil jika dibandingkan dengan atribut lainnya, sehingga dapat disimpulkan bahwa dukungan informasi yang terkandung dalam atribut tersebut terhadap output yang dicapai sangat kecil. Maka atribut tersebut akan dipangkas dan tidak terpilih sebagai atribut untuk decision tree. Berikut merupakan hasil klasifikasi data menggunakan RapidMiner

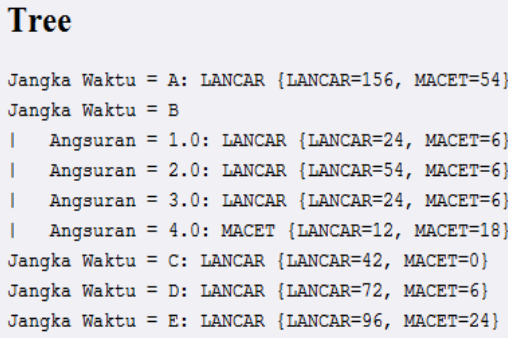

Sumber : Hasil Data Penelitian (2019)

\section{Gambar 41. Hasil Data Klasifikasi Dengan RapidMiner 5.3}

Kemudian dapat terlihat bahwa setelah diproses dengan RapidMiner diperoleh hasil bahwa, atribut yang dipilih dalam pembentukan decision tree hanya atribut Jangka Waktu dan Angsuran. Sedangkan atribut Plafond an Pricing lansung terpangkas dari decision tree. Maka dapat disimpulkan bahwa dengan jumlah dan jenis data yang ada hanya dibutuhkan beberapa atribut untuk mendapatkan kelas hasil dari dataset tersebut. Decision tree yang dihasilkan, seperti gambar dibawah ini: 
Tabel 3. Keterangan Rule Pohon Keputusan

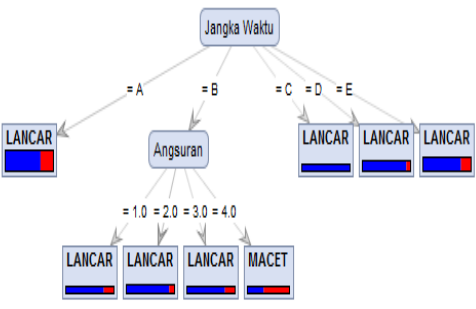

Sumber : Hasil Data Penelitian (2019)

\section{Gambar 52 Decision Tree Analisis Menggunakan RapidMiner 5.3}

Berdasarkan hasil pohon keputusan akhir, maka dapat ditetapkan rule sebagai bertikut:

R1 Jika (Jangka Waktu = "A") hasilnya = "Lancar"

R2 Jika (Jangka Waktu = "B") Angsuran 1 maka hasilnya = "Lancar"

R3 Jika (Jangka waktu = "B") Angsuran 2 maka hasilnya $=$ "Lancar"

R4 Jika (Jangka Waktu = "B") Angsuran 3 maka hasilnya = "Lancar"

R5 Jika (Jangka Waktu = "B") Angsuran 4 maka hasilnya = "Macet"

R6 Jika (Jangka Waktu = "C") hasilnya = "Lancar"

R7 Jika (Jangka Waktu = "D") hasilnya = "Lancar"

R8 Jika (Jangka Waktu = "E") hasilnya = "Lancar"

\begin{tabular}{|c|c|}
\hline NO. RULE & DESKRIPSI \\
\hline R1 & $\begin{array}{l}\text { Kelayakan Kredit Nasabah agar tidak terjadi } \\
\text { NPF atau kredit bermasalah jika nasabah } \\
\text { mendapatkan jangka waktu kredit }>24 \text { Bulan }\end{array}$ \\
\hline $\mathrm{R} 2, \mathrm{R} 3, \mathrm{R} 4$ & $\begin{array}{l}\text { Kelayakan Kredit Nasabah agar tidak terjadi } \\
\text { NPF atau kredit bermasalah jika nasabah } \\
\text { mendapatkan jangka waktu kredit }>36 \text { Bulan } \\
\text { dengan angsuran < Rp. } 2,000,000\end{array}$ \\
\hline R5 & $\begin{array}{l}\text { Kelayakan Kredit Nasabah agar tidak terjadi } \\
\text { NPF atau kredit bermasalah jika nasabah } \\
\text { mendapatkan jangka waktu kredit }<36 \text { Bulan } \\
\text { dengan angsuran }>\text { Rp. } 1,000,000\end{array}$ \\
\hline R6 & $\begin{array}{l}\text { Kelayakan Kredit Nasabah agar tidak terjadi } \\
\text { NPF atau kredit bermasalah jika nasabah } \\
\text { mendapatkan jangka waktu kredit }>48 \text { Bulan }\end{array}$ \\
\hline $\mathrm{R} 7$ & $\begin{array}{l}\text { Kelayakan Kredit Nasabah agar tidak terjadi } \\
\text { NPF atau kredit bermasalah jika nasabah } \\
\text { mendapatkan jangka waktu kredit }>60 \text { Bulan }\end{array}$ \\
\hline R6 & $\begin{array}{l}\text { Kelayakan Kredit Nasabah agar tidak terjadi } \\
\text { NPF atau kredit bermasalah jika nasabah } \\
\text { mendapatkan jangka waktu kredit }>72 \text { Bulan }\end{array}$ \\
\hline
\end{tabular}

Sumber : Hasil Data Penelitian (2019)

\section{Hasil Akurasi}

Hasil akurasi proses nominal $\mathrm{x}$ validasi maka dihasilkan nilai Confusion matrix sebagai berikut:

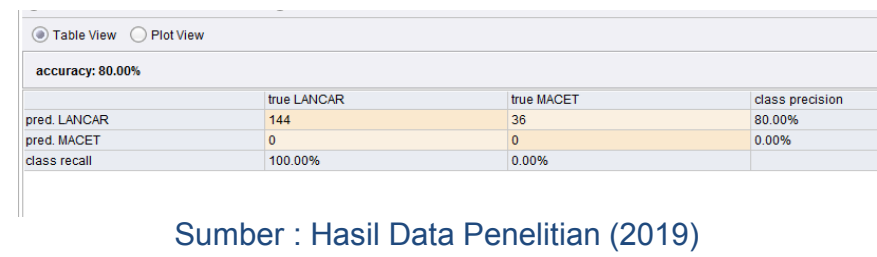

Gambar 6. Table View Accuracy 
PerformanceVector

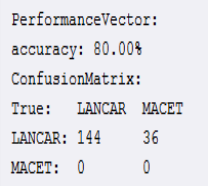

Sumber : Hasil Data Penelitian (2019)

\section{Gambar 7. Hasil Performance Vector}

Berdasarkan hasil dari Performance vector dengan Confusion matrix maka didapatkan hasil dari:

$\begin{array}{ll}\text { Accurasy } & =80 \% \\ \text { Precision } & =100 \% \\ \text { Recall } & =0 \%\end{array}$

\section{E. KESIMPULAN}

Berdasarkan hasil analisis pada pembahasan dapat diperoleh kesimpulan dari algoritma decision tree C4.5 dalam menganalisa data nasabah kredit untuk menghasilkan kelayakan nasabah penerima kredit sangat efektif karena didapat sebuah pola penentu utama yaitu dari faktor Plafon dan Jangka Waktu yang sangat berpengaruh sekali dalam menentukan kelayakan nasabah menerima kredit dengan menghasilkan nilai akurasi pada aplikasi rapidminer 5.3 sebesar $80 \%$, Precision sebesar $100 \%$ dan Recall sebesar $0 \%$ sehingga perusahaan dapat meminimalisir resiko yang akan terjadi.

\section{DAFTAR PUSTAKA}

Aprilia, dennis, Baskoro, D. A., Ambarwati,L dan Wicaksono, I. S. (2012). Belajar Data Mining Dengan RapidMiner. Jakarta.

Fahmi, I. (2014). Manajemen Perkreditan. Bandung: Alfabeta.

Ihsan, D. N. (2013). Analisis Laporan Keuangan perbankan Syariah. Banten: Jakarta Pers.

Jopie, J. (2010). Analisis Kredit Untuk Account Officer. Jakarta: PT Gramedia Pustaka Utama.

Kamagi, D. H., \& Hansun, S. (2014). Implementasi Data Mining dengan Algoritma Dengan Algoritma C4.5 Untuk Memprediksi Tingkat Kelulusan Mahasiswa. ULTIMATICS, VI No.1.

Khasanah. (2017). Penerapan algoritma untuk penentuan kelayakan kredit, Jurnal Techno Nusa Mandiri, Vol.XIV. 9-14
Kusrini, \& Taufiq, L.E. (2013). Algoritma Data Mining. Yogyakarta: Andi Offset.

Larosa, D. T. (2012). Discovering Knowledge in Data : An Introduction to Data Mining. Inc: John Willey.

Lusinia. (2014). Algoritma C4.5 dalam kelayakan kredit, Jurnal KemTekInfo, Vol.1 no.2, 1-5.

Munir, R. (2011). Algoritma dan Pemrograman (rev. ed.). Bandung: Informatika.

Nugroho, \& Sulistyo, Y. (2011). Implementasi Data Mining Sebagai Informasi. Jakarta.

Rudi Hartanto. (2013). Tutorial RapidMiner 5.3 Decision Tree. IImu Biner , 5.

Sukma, Soleh, Yusrina dan Renita (2015). Analisis kelayakan penilaian kredit menggunakan metode analisa $5 \mathrm{C}$ sebagaian penunjang keputusan kredit pada PT. BPR Hariarta Sedana. Jurnal Nasional Informatika, 1-7.

Susanto, Neneng dan Cepi (2012). Penerapan algoritma $\mathrm{C} 4.5$ untuk meganalisis kelayakan pemberian kredit nasabah. Jurnal STMIK Tasikmalaya, 1-7.

Yuliana, Aradea, Ariyan, \& Satriyo. (2011). Penerapan Decision Tree Untuk Penentuan Pola Data. Jakarta. 